\title{
A ENFERMAGEM E A HUMANIZAÇÃO DO PACIENTE
}

\author{
Lucia Herta Rockenbach'
}

R()CKLNBA(H, L.H. A entermagem e a humanizaçăo do packente. Rev. Bras. Enf., Brasilia, $38(1)$ : 49-54, jan./mar. 1985 .

\begin{abstract}
RESUMO. A autora faz uma análise sucinta dos principais aspectos da enfermagem a serviço da humanização do pdciente. Caracteriza o processo de enfermagem, a integração da equipe de enfermagem e as técnicas de trabalho como instrumeritos a serviço da humanização hospitalar. Enfatiza a motivação da equipe de enfermagem como fator determinante da humanização do paciente. Sugere revisão dos objetivos das instituições, ao contratarem enfermeiros para as atividades de enfermagem, e a destinação de um espaço-horário, dentro da jornada diária, para estudos e reflexões sobre a prática da enfermagem, com a participação de todos os membros da equipe de enfermagem.
\end{abstract}

ABSTRACT. The author makes a short analysis of main aspects of Nursing, concerning a humanization service to the patient. The nursing process is characterized by the integration of the nursing team and the working techniques as instruments aiming at hospital humanization. She emphasizes nursing team motivation as a determinant factor for the humanization of the patient. The author suggest the review of objectives of the institutions when hiring nurses for nursing activities and the establishment of a period of time, during the work schedule, for studies and reflections on nursing practice, with the participation of all members of the nursing team.

\section{INTRODUÇÃO}

Todos os acontecimentos históricos tiveram uma fase de elaboraçäo da própria história. A enfermagem nasceu há muitos e muitos anos no relacionamento da mãe com o fillho. A nivel doméstico, foram feitos os ensaios da enfermagem, que procura, ainda hoje, manter características de relacionamento de pessoa a pessoa. Com o decorrer dos tempos, a enfermagem procurou seu suporte teórico e sua fundamentação nos princípios cientificos. Vale-se, hoje, do campo de outras ciências, pois utiliza seus postulados e cria as próprias teorias com base nos conhecimentos e saber de outras áreas. A psicologia, antropologia e suciologia sempre mais orientam e esclarecem o relacionamento da equipe de enfermagem com o paciente e os próprios integrantes da equipe, entre si.

A técnica facilmente donuina o homem. Ilá pouco tempo para os vários níveis de reflexão e inter-relacionamento pessoal. Falar em humanização do paciente supõe uma equipe humanizada.

O trabalho da enfermagem, contínuo e ininterrupto, a constante vivência de fortes emoçōes diante da vida muitas vezes em perigo, a permanente adaptação às pessoas fazem com que o pessoal de enfermagem necessite de boas condições de trabalho, para que a assistência prestada seja adequa-

1 Enfermeira, Protessor Titular da disciplina de Administração e Liderança Aplicada a Lnfermagem do Curso de Enfermagem da liscola Superior de Ciências da Saúde e Promoção Social da lilsSC. - Tubarão, SC. Vice-Diretora da İSCSPS. 
da e eficaz. $\mathrm{O}$ ambiente de trabalho da enfermagem é tão hostil quanto é hostil a situação de vida que leva a maioria da população brasileira. Não é o uniforme, muitas vezes branco, que, de repente, muda o cidadão comum em um super-homem livre de emoções, estresse e problemas da vida diária. $\mathrm{O}$ próprio desenvolvimento da enfermagem como profissão tem sido retardado pelas condições adversas em que atua a equipe de enfermagem. Os altos custos da manutenção dos hospitais e a defasagem na remuneração dos serviços prestados tendem a piorar esta situação ora vigente. Temos notado que a motivação dos trabalhadores de enfermagem decresce dia-a-dia, e a rotatividade em busca de melhores condiçðes em outros setores tem se acentuado ultimamente.

A persistir esta situação, como poderemos falar em humanização do paciente, se antes não podemos constatar a presença de equipes de enfermagem humanizadas?

O compromisso maior da enfermagem é com a população. Não só no sentido de prover uma ótima assistência por ocasião da hospitalização. Os compromissos vão além do hospital, no sentido de se dar orientaçðes e, mesmo, programar uma educação para a alta. Se o hospital é proposto como centro irradiador de saúde, então seu objetivo é também promover, manter e recuperar a saúde do indivíduo, dos grupos e da comunidade. Faz parte da humanização oferecer condiçðes de saúde mais adequadas através da orientação e acompanhamento por ocasião da alta hospitalar.

$\mathrm{Na}$ constante luta pela sobrevivência, a rede hospitalar pode, também, ser tentada a relegar a assistência ao paciente a segundo plano. Aliás, a filosofia da administraçāo determina quem é o centro das maiores atenções. Pode até ser o capital acumulado! A super especialização do pesscal e equipamentos nem sempre é o que a grande maioria dos pacientes necessita. Uma redistribuição dos recursos tinanceiros disponíveis talvez implicasse na otimização dos serviços.

Tanto a equipe de enfermagem como o paciente emergem deste ambiente brasileiro onde a riqueza se concentra sempre mais na mão de poucos em detrimento da pobreza de muitos.

A persistir esta situação, a humanização do paciente e da equipe de enfermagem se torna praticamente inviável. Todo o esforço é válido quando direcionado ao tempo mínimo em que o paciente está internado. Ao menos nestes momentos lhe seja dado o carinho, a assistência e o respeito que merece como pessoa.

\section{FUNDAMENTAÇÃO DA ENFERMAGEM E HUMANIZAÇÃO DO PACIENTE}

Em que se baseia a enfermagem para dizer que sua prática visa à humanização do paciente?

A enfermagem como ciência tem o seu saber teórico-científico e também o senso comum. Ela acredita na pessoa como um todo. Havendo desequilíbrio de algum dos sistemas orgânicos, poderá haver interferências em outras áreas orgânicas ou mesmo desequilíbrios de ordem social, nutricional e outros. A grande preocupação da enfermagem está em contribuir para que se restabeleça o mais rápido possível a homeostase, isto é, para que se restabeleça o meio interno constante, modificado pela doença. Neste particular, vale-se dos princípios da fisiologia. Como dizíamos, a enfermagem acredita no homem como um todo. Sua fundamentação científica é buscada principalmente nas ciências naturais (anatomia, fisiologia, microbiologia, patologia) e nas ciências sociais (psicologia, sociologia, antropologia). Dada a necessidade da fundamentação da enfermagem como ciência. decorre que há razôes suficientes para que toda a equipe de enfermagem seja estimulada a estudos e atualização permanentes. A reflexão diária e os aprofundamentos mensais são exigéncia mínima para um bom desempenho das ações integradas no cuidado ao paciente. A adaptaçāo diária da equipe de enfermagem às novas situações e à rotatividade de pacientes requer conhecimentos de relações humanas que se fundamentam na psicologia. É impossível lutar pela homeostase psicológica do paciente, se os integrantes da equipe de assistência de enfermagem estão desequilibrados na satisfação de suas necessidades psicossociais.

Esta fundamentação científica da enfermagem é aplicada na execução das técnicas que são instrumentos para alcançar seu objetivo. Nos primórdios do cristianismo, a preocupação ligava-se à salvação da alma do paciente. Foi o modelo religioso da enfermagem. Os hospitais eram, até o século XVIII, instituiçōes de assistência aos pobres. As ações de enfermagem objetivavam trazer alívio à alma do paciente. A própria higiene, cuidados com as feridas, os chás, a alimentação, a limpeza do ambiente e o cuidado com as roupas eram praticados para alívio da alma. Com a enfermagem científica, que preconiza o homem como um todo, há necessidade da fundamentação destas práticas à luz das ciências. As instituiçōes hospitalares, hoje, não podem se ater aos empreguismos ou à superficialidade. Dentro dos princípios administrativos, as tarefas 
da enfermagem devem ser agrupadas para fins de economia de tempo e de maior presteza na execução. Os cuidados de enfermagem são distribuídos segundo o princípio da divisão de trabalho: um presta cuidados higiênicos a todos os pacientes da unidade, outro verifica os sinais vitais, outro distribui a medicação e outro encam inha os pacientes aos exames complementares e de diagnóstico. Nesta distribuição de tarefas também deve ser atendida a pessoa do paciente. Os horários est abelecid os devem respeitar os hábitos domésticos, incluindo as devidas orientações ou reorientações, se for o caso. A execução das técnicas de enfermagem é excelente oportunidade para o diálogo sobre ações de saúde preventiva, promoção à saúde e educação para a alta hospitalar.

Aplicando-se os princípios de administração cientifica, facilmente se perdem os princípios de humanização do paciente. O equilíbrio entre os dois será o ponto ótimo da assistência de enfermagem. Este prejuízo ao paciente é tanto mais sério quanto mais centrado for o capital. A centralização das atenções no paciente e na equipe de trabalho imprime linha diferente de atuação do que aquela do capital.

A inspiração, o ideal, as características da personalidade de cada integrante da equipe de enfermagem são traduzidos através da execução das técnicas e o conjunto das ações desenvolvidas na rotina diária de uma unidade de internação. Todo o ambien te, ar, luz, higiene, solidariedade, silêncio, harmonia são determinados pelo maior ou menor grau de conhecimento e integração da equipe de trabalho.

\section{FUNÇÕES DA EQUIPE DE ENFERMAGEM A SERVIÇO DA HUMANIZAÇÃO}

A equipe de enfermagem, antes de atuar junto ao paciente, precisa estar integrada como grupo de pessoas, cujo objetivo é comum: o bem-estar do paciente, que deve, dentro do menor prazo possível, ser capaz de voltar a realizar seu autocuidado.

Toda a equipe tem o seu líder. No caso da equipe de enfermagem, a liderança é atribuída ao enfermeiro. Não significa que seja o melhor da equipe. Já foi privilegiado pelo acesso às universidades. A ele cabe coordenar as ações de enfermagem, respeitando profundamente a individualidade do paciente $\mathrm{e}$ a individualidade dos integrantes da equipe de enfermagem. Só uma equipe de enfermagem humanizada é que poderá humanizar o paciente. Cabe ao enfermeiro atuar no processo da assistência de enfermagem, identificando as necessida- des de saúde do paciente e sua família; fazer diagnóstico de enfermagem e, a partir dele, elaborar o plano de cuidados e executá-lo junto com a equipe, delegando as funções mais simples aos técnicos, auxiliares e atendentes de enfermagem. Cabe-lhe também avaliar os cuidados de enfermagem. A equipe de enfermagem precisa estar constantemente preocupada em melhorar o seu nível de assistência ao paciente. Deve, portanto, estar animada pelo espírito de crítica e aprofundamento de seus conhecimentos. Isso pode ser alcançado através de reuniões de serviço, durante, pelo menos, quinze a vinte minutos diários e, mensalmente, de um estudo mais prolongado. Todos os membros da equipe de enfermagem são capazes de estudar e apresentar os resultados de seus estudos. A prática diária, a leitura de artigos sobre a saúde, a observação desenvolvida pelos treinamentos em serviço também capacitam o atendente para a fundamentação de sua prática. É aconselhável que a equipe se organize e estimule os seus integrantes a participarem de atualizações, jornadas de enfermagem e outros que são promovidos em vários centros de estudos em enfermagem e associações de classe.

Cabe ao enfermeiro participar da equipe administrativa do hospital orientando todas as ações que visem ao bom andamento dos serviços. Evite-se desviar o enfermeiro para as ações administrativas que podem ser exercidas por outros agentes administrativos. Que as ações administrativas do enfermeiro sejam ações de administração da enfermagem.

A enfermagem precisa sempre mais fundamentar a sua assistência. Para tanto, deve reservar um tempo para realizar pesquisas de enfermagem. É um procedimento que auxilia muito a eliminação de problemas que, às vezes, parecem sem soluções, ou cuja causa é desconhecida. Um exemplo prático são as infecções que aparecem nos berçários. É relativamente fácil eliminar a causa, após conhecido o agente da infeç̧ão.

$\mathrm{O}$ desempenho da enfermagem pressupõe a contínua atualização da equipe com referência aos progressos científicos e tecnológicos. Não só a equipe de enfermagem, mas dos próprios dirigentes de hospitais, para que possibilitem a atuação consciente da enfermagem. O dirigente hospitalar é doutor em administração e não tem obrigação de sê-lo em enfermagem. Porém, a prática tem demonstrado que a contínua atualização do administrador lhe proporciona capacitação para ouvir e atender às reivindicações justas do pessoal que lhe é subordinado. Além disso, passa a solicitar subsí- 
dios dos diversos sciores para estabelecer gestöes junto aos órgãos de administração central e conveniados.

Antes de se falar em humanização do paciente, é importante estudar e avaliar a humanização da equipe de enfermagem e, por que não dizê-lo, a humanizaçao de toda a comunidade de funcionários da instituição.

\section{O PROCESSO DE ENFERMAGEM COMO INSTRUMENTO DE HUMANIZAÇÃO DO PACIENTE}

A enfermagem, como ciência que procura sempre maior fundamentação dos seus trabalhos, vem desenvolvendo teorias que a consagram delinitivamente como ciência. () paciente se comunica continuamente com a enfermagem, informando sobre ele e suas condiçōes. A entermagem collhe as informaçōes por meio da sua ubservação e capacidade de comunicação. Este nível, de apenas registrar o observado ou informado, é o mais comum dos serviços de enfermagem. É o primeiro estágio. Bastante rudimentar, quando único. As informações deste nivel podem ser passadas verbalmente ou por escrito. Na maioria das instituiçōes hospitalares de Santa Catarina, a transmissão é feita verbalmente, registrando o mímimo de intormaçōes que poderiam levar o paciente a realizar seu autocuidado num espaço de tempo bem menor. Lembramos que um dos grandes objetivos da enfermagem é auxiliar o paciente a reaver suas condições de autocuidado no menor tempo possivel. () segundo nivel de atuação da enfermagram seria o de comparar os resultados obtidos através da observação e informaçảo com os indices considerados ótimos em saúde. Reconhece as diferenças destes indices, registra-os e contribui para o rápido restabelecimento do paciente, pois, inclusive, os profissionais da medicina e outros profissionais se valerão das anotaçōes para a sua conduta terapéutica. Um terceiro nivel de atuação da enfermagem permitir-lhe-a funcionar como interventor das situações observadas e comparadas com índices considerados ótimos. Imediatamente, desenvolverá ações para diminuir a diferença entre o estado atual e o desejado. Exemplo: num paciente que se apresenta com hipertermia, poderiam ser aplica. dos os três níveis de atuação da enfermagem.

Se a assistência de enfermagem na realidade visa à humanização do paciente, os instrumentos e a metodulogia empregados precisam encontrar o seu respaldo técnico-cientifico. A integração multi- profissional desejada depende muito da competência técnica e humana da enfermagem. Mais uma razao para incentivar a equipe de enfermagem a realizar estudos sistemáticos, visando ao aperfeiçoamento e fundamentação da sua prática. A pessa humana como centro das atenções deve ser respeitada também no manejo adeçuado da recuperaçào de sua saúde. Visando a ordenar as intervenções, está sendo adotado o processo de enfermagem como instrumento sistemático do estágio de maturidade em que entra a profissão atualmente. É o sinal certo da melhoria do nível teórico da enfermagem também no Brasil. As auditorias em enfermagem valorizam as instituições em que o processo de enfermagem é aplicado. O processo de enfermagem hoje é aceito como instrumento científico de trabalho da enfermagem. Já foi avaliado e considerado eficiente, caracterizando-se pela sucessão dinâmica das várias fases e seu inter-relacionamento.

O primeiro passo do processo de entermagem é o histórico de enfermagem. É um roteiro sistematizado para levantar dados do ser humano que identifiquem os seus problemas. Estes dados serão significativos para a enfermagem que coloca sua crença no homem como um todo. A sua história é a própria determinante de seu estado atual. Os desequilibrios biopsicossociais são partes integran. tes de sua história familiar e social.

O levantamento dos dados e a observação permitem estabelecer o diagnóstico de enfermagem, que é o segundo passo do processo. Neste segundo passo, é realizada a identificaçāo das necessidades humanas básicas que não foram atendidas e que causaram a internação. Faz parte do diagnóstico de enfermagem, também, a determinaçāo do grau de dependência do atendimento de enfermagem. Em determinadas situaçōes, a enfermagem terá que fazer tudo pelo paciente. É o grau de dependência máxima, ou total. Em outras situaçoes, basta ajudar o paciente ou orientar como fazer. Numa dependência relativa poderá ser suficiente supervisionar as açōes do paciente ou ainda encaminhá-lo a outros profissionais para seu completo ajustamento de saúde.

Uma vez feito o diagnóstico, encaminha-se o plano assistencial. Nada mais é do que o plano global de assistencia de enfermagem diante do diagnóstico estabelecido. É a terceira fase do processo de enfermagem. Este plano é baseado nos problemas detectados através do histórico, nas necessidades afetadas e no grau de dependéncia estabelecido. Este plano é dinâmico. À medida que forem 
surgindo novas necessidades, acontecerá a implementaçăo.

A constante avaliação do plano assistencial fornece os dados ao quarto passo: plano de cuidados ou prescrição de enfermagem. É o roteirơ que coordena a ação da ęjuipe de enfermagem diariamente, possıbilitando $u$ adequado atendimento às necessidades básicas e específicas de cada ser humano.

A resposta à assistência prestada ao paciente é registrada diariamente e sucessivamente, constituindo-se no quinto passo do processo. É denominado evolução de enfermagem.

Finalmente, como último passo, é dado u prognóstico de enfermagem. É a estimativa da enfermagem quanto à capacidade do paciente de realizar o seu autocuidado, não mais dependendo da equipe de enfermagem. Em todo o tempo da aplicação do processo de enfermagem, são dadas orientaçoes de como melhorar o nível de saúde. Por ocasião da alta hospitalar, o paciente deve estar capacitado para a autocondução do equilíbrio no atenclimento de suas necessidades básicas. Através da eficiência dos cuidados de enfermagem prestados e da eficácia da educação para a alta, poderiam, talvez, ser reduzidas as reinternações de pacientes, que são tão comuns entre nós. Aí se percebe a urgente necessidade de unir a educação para a saúde e a recuperação de desequilíbrios sérios ocorridos.

A enfermagem planejada tem muitos passos a dar. Não basta à equipe ter habilidades, observação, comunicação, destreza manual, criatividade. É preciso dar condiçðes para que esta equipe possa aplicar o método cientifico e os princípios cient íficos na execução de suas atividades. A desumanização da equipe, por falta de condições de trabalho, provoca a desumanização do paciente, que deixa de receber os cuidados a que tem direito. Após poucos dias de convivência com a família, volta ao hospital, porque não recebeu orientaçōes suficientes e adequadas para o seu completo restabelecimento.

O enfermeiro egresso das escolas de enfermagem há mais de dez anos está sendo capacitado para a aplicação do processo de enfermagem. São bem poucas as unidades hospitalares que o adotam através do serviço de enfermagem. A contratação do enfermeiro para administrar ações que poderiam ser administradas por outros profissionais o desvia do cuidado direto ao paciente. $O$ excesso de atividades burocráticas dificulta a implantação do plano assistencial e até do plano de cuidados diá- rio. A experiencia de permitır au entermeiro ordenar a assisténcia de enfermagem, sobretudo em relação aos pacientes com maior número de necessidades afetadas, tem aumentado consideravelmente a realização profissional de toda a equipe que verifica significativa redução dos dias de internaçăo dos pacientes. Neste estilo de assistência as instituições passariam a ter a sua definição original: local de repouso onde o ser humano reencontra o nível ótimo de saúde desejado. O grau de satisfação do paciente seria bem mais elevado, pois elevado estaria também o grau de satisfação da equipe de enfermagem que veria melhores resultados de sua atuação.

\section{A MOTIVAÇÃO DA EQUIPE DE ENFERMAGEM E A HUMANIZAÇÃO DO PACIENTE}

A motivação é fator decisivo em qualquer empreendimento individual ou coletivo. É um recurso de adninistração a ser utilizado sempre que se requer a cooperação do grupo, para alcançar determinado objetivo. "É um estado interno que dá energia, torna ativo ou move o organismo, dirigindo ou canalizando o comportamento em direção a objetivos" (MANZOLLL)".

"Motivação é o empenho de aumentar ou manter tão alto quanto possível a capacidade de um individuo, a fiın de que este possa alcançar excelência na execução das atividades das quais dependem o sucesso ou o fracasso da organização a que pertence" (MANZOLLI) ${ }^{9}$.

"Alcançar excelênca na execução das atividades", segundo o autor. Com muito mais razão se aplica este conceito, quando as atividades serão executadas diretamente junto à pessoa prejudicada no seu equilibrio organico, independente da causa desencadeante.

A motivação da equipe de entermagem nãi reside no conforto material e remuneração linanceira por trabalhos prestados. Como qualquer outra pessua, há os motivos idealistas comó justiça, bondade, cumprimento do dever, honestidade, autocrítica, cooperação, ética e solidariedade. Talvez a observação, por parte da chefĩa, seja descuidada destes aspectos, por considerar normal esta motivação. Por que niõo estimular o funcionário, lembrando suas atitudes positivas em relação aos pacientes? Em escala crescente estão as motivações primárias ou biológicas, dada a dificuldade por que passa a população para manter sua vida (fome, sede, manutenção da família ). Não se pode esque- 
cer que tanto o paciente como os integrantes da equipe emergem deste contexto sócio-cultural. As necessidades humanas, tensões, conflitos, frustrações, renúncias são outras tantas motivações que impulsionam as pessoas no seu agir diário. $\mathrm{Na}$ maioria das vezes, constatamos que of fator sobrevivência caracteriza as maiores motivações. Os índices de aumento salarial, que deixam de acompanhar até a inflação vigente, levam às vezes a solicitar até as taxas de insalubridade. Não que o ambiente seja considerado insalubre no seu grau máximo. A razão mesmo é aumentar um pouco a renda familiar.

A motivação muitas vezes exige mudanças. Toda mudança exige esforço em direção a alguém. Nem sempre os objetivos das instituições permitem ou favorecem estas mudanças. Os próprios dirigentes superiores resistem em mudar suas estratégias e aceitar inovações de atitudes menos democráticas. E a motivação é utilizada na administração democrática como estímulo aos aspectos participativos. $\mathrm{Na}$ administração autocrática, as motivações são mais instintivas, como medo, repressão e outros. Os grandes opressores são, às vezes, os chef es de equipe, porém quase sempre orientados pela direção superior que não quer ser mal vista e assumir seu processo autocrático.

A motivação é dinâmica. Depende da personalidade dos indivíduos e da situação em que se encontrem. Cabe ao grupo conceder a cada indivíduo o seu espaço e respeitar os seus estágios motivacionais.

\section{CONCLUSÃO}

Diante do exposto, podemos dizer que sempre se faz mais necessário o aprimoramento da equipe de enfermagem não só como técnicos, mas, sobretudo, como pessoas que se comunicam, às vezes num plano de grande empatia com os pacientes. $\mathrm{O}$ preparo profissional da enfermagem deveria incluir, necessariamente, treinos de ajustamento pessoal e vivências grupais. Não só as escolas deveriam se preocupar com estes aspectos, mas as próprias instituições hospitalares, nos seus programas de formação permanente, deveriam incluir, sistematicamente, estudos e vivências terapêuticas de personalidade.

O nível de aspiração da equipe de enfermagem se situa um pouco além da rotina diária. Como pessoas que emergem da sociedade comum trazem condicionamentos e esperanças de vida qualitativa e pretendem, junto com o paciente e seus familiares, construir um mundo mais saudável e condizente com os direitos da pessoa humana.

Estas reflexões pretendem revisar um pouco a prática da enfermagem e lembrar que, segundo Dra. Wanda de Aguiar Horta, enfermeiro é gente, cuidando de gente.

ROCKENBACH, L.H. Nursing and patient humanization. Rev. Bras. Enf., Brasília, 38(1): 49-54, jan./mar. 1985.

\section{REFERÉNCIAS BIBLIOGRAFICAS}

1. ALMEIDA, M.C.P. de. $O$ saber, a saude e a pesquisa em enfermagem. In: SEMINÁRIO DE PESQUISA EM ENIERMAGEM, 39̣, Florianópolis, 1984. (mimeografado).

2. CONSElho federal de Enfermagem. Código de deontologia de enfermagem. Rio de Janeiro, 1978.

3. DANIEL, L.F. A enfermagem planejada. São Paulo, Cortez \& Moraes, 1977.

4. liAVRETTO, A. O doente - razão de ser do hospital: subsidios para um trabalho de pastoral na área da saúde. Santos, s. c.p., 1977.

5. GATTÁS, M.L.B. Relacionamento interpessoal enfermeiro-paciente. Rev. Paul. Enf., São Paulo 4 (2): 59-61, abr./jun. 1984.

6. Gelain, I. Deontologia e enfermagem. São Paulo, I:PU, 1978.

7. HORTA, W. de A. Processo de enfermagem. São PauIo, EPU, 1979.

8. LEPAGNEUR, H. Vale a pena dizer a verdade ao doente? São Paulo, 1981. (mimeografado).

9. LOPES, T. de V.M. Motivação no trabalho. Rio de Janeiro, Ed. da Fundação Getúlio Vargas, 1980.

10. MANZOLLI, M. Psicologia em enfermagem: teoria e pesquisa. São Paulo, Savier, 1981.

11. MINZONI, M.A. Atitudes do profissional de enfermagem frente a pessoa que requer ajuda. Ribeirão Preto, 1983. p. 3 (mimeografado).

12. ORLANDO, I.J. O relacionamento dinâmico enfermeiro-paciente. São Paulo, EPU, 1978.

13. PAIM, R.C.M. Problemas de enfermagem e terapia centrada nas necessidades do paciente. Rio de Janeiro, União dos Cursos Cariocas, 1978.

14. ROSEMBERG, R. A pessoa como centro. São Paulo, EPU, 1977.

15. SOUZA, E. de F. Novo manual de enfermagem. Rio de Janeiro, Ed. Bruno Buccini, 1972.

16. TRAVELBEE, J. Intervención en enfermeria psiquiátrica. Carvajal, Organización Panamericana de la Salud, 1972. 